\title{
STUDY OF KINEMATIC VISCOSITY, VOLATILITY AND IGNITION QUALITY PROPERTIES OF BUTANOL/DIESEL BLENDS
}

\author{
L. F. P. Brandão ${ }^{1,2}$ and P. A. Z. Suarez ${ }^{2 *}$ \\ ${ }^{1}$ Agência Nacional do Petróleo, Gás Natural e Biocombustíveis, SGAN 603, Módulo H, 70830-030, Brasília - DF, Brazil. \\ ${ }^{2}$ INCT - Catálise, Laboratório de Materiais e Combustíveis, Instituto de Química, Universidade de Brasília, \\ Campus Universitário Darcy Ribeiro, 70904-970, Brasília-DF, Brazil.
}

(Submitted: July 14, 2017 ; Revised: January 29, 2018 ; Accepted: March 5, 2018)

\begin{abstract}
The alternative use of butanol in blends with diesel has attracted the attention of many researchers worldwide for its possibility to overcome some barriers observed for other lower chain alcohols. Viscosity, volatility and ignition quality are critical characteristics of a fuel intended for use in compression ignition engines. In this paper, the kinematic viscosity, atmospheric distillation and cetane number of butanol/diesel blends in proportions of up to 30 mass\% were determined and compared with Brazilian diesel specifications. Two types of diesel matrices $10 \mathrm{ppm}$ (S10) and $500 \mathrm{ppm}$ (S500) sulfur and two butanol isomers ( $n$ - and iso-butanol) were tested. Results showed that both kinematic viscosity and cetane number were reduced with the increase of the butanol content in blends. Butanol provided an intense increase of the blend volatility, resulting in pronounced effects on the distillation curve shape, in relation to that observed for pure diesel.

Keywords: Butanol; Cetane number; Ignition quality; Kinematic viscosity; Volatility.
\end{abstract}

\section{INTRODUCTION}

The proposal of using oxygenated compounds in fuels is not recent and has been investigated for at least half a century (Kumar et al., 2013). Over the last decades, alcohols such as methanol and ethanol were considered feasible components for use as additives in diesel, but characteristics such as low solubility in hydrocarbons, high hygroscopicity, low density, low cetane number and high octane number were limiting factors to the advance and development of these blends (Kim et al., 2011 Kozak, 2011).

Viscosity has a strong relationship with atomization quality, droplet size and fuel jet penetration into the injection system, influencing the timing and combustion quality. Volatility measures the tendency of a fuel to vaporize under a given condition of operation and keeps a close relationship with the engine performance and power. The ignition quality, one of the most important characteristics of dieselbased fuels is related to the combustion efficiency and energy production, noise level, engine start and emissions.

A large number of studies have evaluated the effects that oxygenated compounds exert on fuel properties, performance and emissions. The tert-butyl and tertamyl ethers, glycol ethers, alcohols and fatty acids esters, which have been historically more widespread solutions due to properties similar to those of diesel, are typical examples of compounds most commonly tested or commercially employed. Belincanta et al. (2016) studied the effects of ethanol over some gasoline properties (miscibility, volatility and elastomeric materials compatibility). Several studies in the literature have investigated the properties of alcoholdiesel blend fuels (Kumar et al., 2013; Dogan, 2011; Mehta et al., 2010; Altun et al., 2011; Giakoumis et al. 2013; Chen et al., 2013; Sukjit et al., 2012; Atmanl1 et

\footnotetext{
* Corresponding author: +55-61-31073850, E-mail address: psuarez@unb.br
} 
al., 2014; Barrios et al., 2014; Valentino et al., 2012; Rakopoulos, 2010).

Alcohols have been frequently investigated as additives for use in both conventional (CI) and not conventional diesel engines (e.g., HCCI, PCCI), since the low volatility and high reactivity of common diesel fuel make it non-conducive for some types of engines. In order to improve the combustion mechanism and emission levels (such as auto-ignition timing, heat release rate and exhaust gas emission), different strategies have been tested, including the use of fuels with different characteristics. For instance, alcohols have been commonly used in blends with diesel to prolong the ignition delay and, thus, increase the premixed combustion phase, providing higher heat release rate (Zheng et al., 2015; Boretti, 2012; He et al., 2014).

More recently, butanol, popularly known as butyl alcohol, has attracted growing interest of the industry and researchers as an alternative fuel due to its satisfactory solubility in heavier hydrocarbons and moderate cetane number, which allows its addition in diesel in larger proportions (Kumar et al., 2013, Garcia et al., 2011). Also, compared to other lower chain alcohols, butanol provides a kinematic viscosity closer to diesel, which makes it more compatible with injection systems used in most of diesel engines. Otherwise, a too low viscosity could compromise the self-lubrication of the high pressure injection apparatus, reducing its life-time.

Different physical-chemical characteristics of prepared biobutanol/diesel fuel blends, in the range from 0 to $100 \mathrm{vol} \%$, were tested by Hönig et al. (2015) using methods compliant to standard EN 590. In another work, Lapuerta et al. (2010) evaluated the stability, lubricity, viscosity, and cold-flow properties of $\mathrm{C} 1$ to $\mathrm{C} 5$ alcohol/diesel blends in concentrations varying from 1 to $90 \mathrm{vol} \%$. Ramirez et al. (2014) described the effects of blending 5, 10 and $20 \mathrm{vol} \%$ of phytol, a heavy alcohol $\left(\mathrm{C}_{20} \mathrm{H}_{40} \mathrm{O}\right)$, with diesel for use in a heavy-duty compression-ignition engine, concluding that phytol may be a suitable agent for blending with diesel fuel for ignition by compression engines (CI). The behavior of different fuel properties of bioethanol-diesel blends from 5 to $25 \mathrm{vol} \%$ and the impacts of different co-solvents tested on blend phase stability were evaluated by Matuszewska et al. (2013).

In some cases, butanol is added to biodiesel/diesel to improve some specific quality parameters in ternary blends. Imtenan et al. (2015) used a four-cylinder engine test bed to investigate the use of $n$-butanol, in proportions of $5 \mathrm{vol} \%$ and $10 \mathrm{vol} \%$, as an additive to improve performance and emission of a binary diesel/ tamanu biodiesel blend (designated as AL20). Early start of combustion and higher heat release rate (HHR) were observed for blends with $5 \mathrm{vol} \%$ of butanol compared to AL20. In terms of performance, lower brake specific fuel consumption (BSFC), lower brake specific energy consumption (BSEC) and higher brake thermal efficiency (BTE) were achieved. Emissions of $\mathrm{NO}, \mathrm{CO}$ and smoke opacity were also reduced. Better performance and emission characteristics were achieved for blends containing $10 \mathrm{vol} \%$ of butanol.

In another work, Norhidayah et al. (2017) presented the use of palm-methyl-ester as co-solvent in ethanol/diesel blends as an alternative to increase both kinematic viscosity and calorific value. Mehta et al. (2012) tested important properties of ethanol and butanol/diesel blends using the biodiesel as a surfactant to stabilize the blends. The cetane number and thermal properties of vegetable oils/butan-1-ol/diesel blends in the percentage ratio of 10:10:80 were experimentally investigated by Lujaji et al. (2010).

Chen et al. (2017) used a laser diagnostics and chemical kinetic modeling to investigate the effects of butanol on the formation of polycyclic aromatic hydrocarbons (PAHs) and soot when added to a T20 diesel surrogate ( $80 \mathrm{vol} \% n$-heptane and $20 \mathrm{vol} \%$ toluene). The results showed dependence between PAH/ soot formation versus the butanol content (dominant factor) and its carbon structure. Blends with branched butanol isomers resulted in a higher formation of PAH and soot than those with linear isomers.

A study of strategies to reduce soot emissions under early-injection conditions on a modified single-cylinder diesel engine was performed by Liu et al. (2015) evaluating different engine operating parameters and fuels. The soot emission was reduced under the following conditions: 1) at injection timings higher than $-55^{\circ}$ CA ATDC, suppressed by the lowered combustion temperature conditions; 2) for EGR combined with higher intake pressure; and 3) increasing intake and coolant temperature at injection timing later than $-55^{\circ} \mathrm{CA}$ ATDC. Soot emissions were little affected by an injection pressure increase (up to $140 \mathrm{MPa}$ ), but significantly reduced with tested diesel/ gasoline and diesel $/ n$-butanol blends.

Modeling (Full Factorial design) and experimental investigations aiming at emissions reduction and engine performance were carried out by Nayyar et al. (2017) testing n-butanol/diesel blends (10 to $25 \mathrm{vol} \%$ ) on a small size, modified and variable compression ratio (VCR) diesel engine, operating at a constant speed of $1500 \mathrm{rpm}$ and variable engine load $(12,16,20$ and $24 \mathrm{Nm}$ ). Butanol provided a significant reduction in emissions $\left(59.56 \%\right.$ in smoke and $15.96 \%$ in $\left.\mathrm{NO}_{\mathrm{x}}\right)$ and a slight improvement in engine efficiency $(5.54 \%$ in thermal efficiency), with optimum results obtained at injection time of $23^{\circ} \mathrm{CA}$ BTDC / injection pressure of $210 \mathrm{bar}$ and higher compression ratio of 18.5 and 19.5 for pure diesel and blends with $20 \mathrm{vol} \%$ of butanol, respectively. 
The effects of butanol isomers on combustion and emissions on a modified single-cylinder diesel engine were also studied by Zheng et al. (2015) blended in proportions of $20 \mathrm{vol} \%$ and $40 \mathrm{vol} \%$ in diesel. Investigations covered both conventional diesel combustion and low temperature combustion, over a range of EGR from $0 \%$ to circa $65 \%$. A retarded combustion phasing, higher premixed combustion fraction, higher thermal efficiency and significant soot emission reduction were observed for butanol/diesel blends compared with pure diesel. No significant differences were achieved for combustion and emissions characteristics varying the butanol isomer in blends.

Zheng et al. (2015) also evaluated the effects of a two stage injection (pilot-main and main-post) on combustion and emission characteristics. A singlecylinder diesel engine was used, under a high EGR $(46 \%)$ condition and different fuels were tested. The use of gasoline and/or $n$-butanol in blends with diesel reduced smoke emissions and induced the increase in maximum pressure rise rate (MPRR). Increasing of the pilot-main interval decreased smoke emissions, whereas a longer main-post interval decreased postheat release rate and prolonged combustion duration. The study concluded that blended fuels were more sensitive to the post-injection variation.

Liu et al. studied the effects of five different fuels blended in proportions of $20 \mathrm{vol} \%$ in diesel, tested over a wide range of EGR rates from $0 \%$ to $62 \%$ to investigate the combustion and emission characteristics on a modified single-cylinder diesel engine. According to the work, the combustion of butanol/diesel blends was similar to those of iso-octane/diesel blends. The oxygen present in the butanol fraction of blends was the main factor for soot reduction, followed by the improvement in the fuel mixing process resulting from the longer ignition delay provided by butanol compared to diesel.

The potential of using $n$-butanol/diesel blends (10 vol $\%$ and $30 \mathrm{vol} \%$ of butanol) on Partial Premixed low temperature (PPCI) combustion were tested by Cheng et al. (2016), focusing on the injection timing/pressure and load rate, on a four-cylinder diesel engine. PPCI could be achieved with lower injection pressure and moderate EGR rate. Long premixed combustion was observed for both early and late injections providing more homogeneous mixtures and, consequently, improving smoke emissions by up to $70 \%$, but a slight increase of $\mathrm{NO}_{x}$ was also related.

It is worth to mention that most of the studies involving ignition quality have been performed based on estimated values of cetane index, calculated from other physical-chemical properties such as distillation points and density (e.g., ASTM D976 or D4737 standard methods). Indeed, as far as our knowledge, very few studies have reported the use of ignition quality testers to evaluate the real impact of oxygenated compounds on the cetane number of diesel blends.

In the present work, kinematic viscosity, distillation and cetane number, three critical diesel fuel properties, were evaluated for prepared butanol/ diesel blends and for respective pure diesel matrices. Experimental analyses were performed by using an automatic viscometer, an automatic distiller and an accurate ignition quality tester (IQT-LM), according to the ASTM D445, D86 and D6890 standard methods, respectively. The effects of linear butan-1-ol and branched 2-methylpropan-1-ol isomers as well as the contribution of sulfur in final blend fuels properties were also considered and discussed.

\section{EXPERIMENTAL SECTION}

\section{Preparation of Butanol/Diesel Blends}

Analytical grade butan-1-ol and 2-methylpropan1-ol standards (min. 99.0\%) were purchased from Vetec, Brazil, and used as received. Two types of pure diesel with different sulfur contents of 10 (S10) and 500 (S500) ppm were provided by Total Distribuidora S.A., Brasilia, DF, Brazil for blend sample preparation.

A total of 48 fuel blends were prepared from the combination of 2 types of diesel matrices and 2 butanol isomers in 12 different contents (from 2.5 up to 30.0 mass $\%$ ). For each blend, pre-calculated masses of the diesel matrix and butanol standard were individually weighed in a semi-analytical balance and then transferred to a $500 \mathrm{~mL}$ amber glass flask to result in the desired final content, in mass $\%$ terms.

\section{Kinematic Viscosity at $40^{\circ} \mathrm{C}$}

The kinematic viscosity of samples was individually measured on an automatic Cannon Instrument Company CAV 2200 viscometer, according to the procedure of the ASTM D445 standard method. In this test, the time that a liquid volume of fuel takes to flow under gravity through a calibrated capillary was measured. Because the blends were prepared with diesel, the silicon bath containing the capillary was adjusted to a constant temperature of $40^{\circ} \mathrm{C}$, controlled by an external thermostatic Julabo bath filled with distilled water and ethylene glycol held at $18{ }^{\circ} \mathrm{C}$. About 10 to $20 \mathrm{~mL}$ of each blend were transferred to Cannon glass tubes and then placed for analysis in the sample slot, one at a time.

The entire procedure was performed in triplicate for each sample. The instrument was previously verified 
with three Cannon certified reference standards (N2, S3 and S6), with nominal viscosity values of 1.964 , 2.963 and $5.798 \mathrm{~mm}^{2} \mathrm{~s}^{-1}(\mathrm{cSt})$ at $40^{\circ} \mathrm{C}$, respectively.

\section{Atmospheric Distillation}

The volatility of blends was tested in an automatic Normalab NDI 450 distiller, according to the ASTM D86 standard method. Until the test was performed, blends were previously kept refrigerated at $4{ }^{\circ} \mathrm{C}$ to avoid volatile compound losses. An exact volume of $100 \mathrm{~mL}$ of each blend was first measured in a Normalab graduated glass cylinder and immediately transferred to a distillation flask. After being emptied, the same glass cylinder was positioned at the condenser tube outlet. To prevent blend from bumping over during evaporation, glass beads were added to the flask. Distillation temperatures were registered by a calibrated PT100 thermocouple, adjusted to the flask. The glass flask containing the blend was properly positioned in the distiller, supported on a $50 \mathrm{~mm}$ central hole ceramic plate and the glass flask arm directed to the condenser tube inlet. The system was heated at a 4 to $5 \mathrm{~mL} \mathrm{~min}^{-1}$ rate and the distilled product collected in the graduated cylinder. The same procedure was repeated for all tested blends.

\section{Cetane Number}

The ignition quality of pure diesel as well as of butanol/diesel blends with 5,10,15,20,25 and 30 mass\% of butanol was tested in an Ignition Quality Tester (IQT-LM) by Advanced Engine Technology Ltd, according to the ASTM D6890 standard method. In this test, the ignition delay between the fuel sample injection and combustion events was measured inside a fixed volume and air compressed chamber at approximately $550{ }^{\circ} \mathrm{C}$. The cetane number was calculated by the IQT software using the ignition delay value obtained in the test, hence the so-called "derived cetane number". The system was previously submitted to a warm-up followed by a routine check of the ultrapure 5.0 nitrogen and synthetic air pressure, responsible for the injection control and charge pressures, in psi.

For the test, approximately $100 \mathrm{~mL}$ of each blend was previously filtered with a $25 \mathrm{~mL}$ glass syringe coupled to a Millipore Millex-HV $0.45 \mu \mathrm{m}$ filter to remove solid contaminants. With the equipment heated, the filtered blend was transferred to the sample tube and the system pressurized. Analyses were completed after 15 pre-injections and 32 injections cycles performed automatically by IQT and the result reported as the mean cetane number value. After each analysis, the system was cleaned with analytical grade iso-octane standard, 99.5 vol\%.

\section{RESULTS AND DISCUSSION}

\section{Kinematic Viscosity at $40^{\circ} \mathrm{C}$}

Kinematic viscosities of 1.973, 2.978 e 5.776 cSt were obtained for preliminarily N2, S3, and S6 reference standards, which are in accordance with the certified values. The analytical grade butan-1-ol and 2-methylpropan-1-ol standards showed a slightly lower value (2.249 and $2.651 \mathrm{cSt}$, respectively) compared to that of pure S10 $(2.673 \mathrm{cSt})$ and S500 diesel $(3.025$ cSt) matrices. Consequently, all the butanol/diesel blends resulted in an overall viscosity reduction trend, proportional to the butanol content.

Excellent repeatability was obtained for measured viscosities using CAV 2200, with standard deviations lesser than of $0.010 \mathrm{cSt}$. As shown in Table 1, the kinematic viscositymeasured forS10 diesel was reduced to up to $2.192 \mathrm{cSt}$ and up to $2.302 \mathrm{cSt}$ when blended with 30 mass $\%$ of butan-1-ol and 2-methylpropan-1ol, which corresponds to percentage reductions of up to $18 \%$ and $14 \%$, respectively. For S500 diesel blends, in Table 2, corresponding reductions of up to $2.378 \mathrm{cSt}$ and up to $2.520 \mathrm{cSt}$ were obtained, respectively. These new values are approximately to $21 \%$ and $17 \%$ lower than the original value of S500 diesel $(3.025 \mathrm{cSt})$.

Despite this, all the viscosity values obtained for blends would meet the specification limits established by the National Agency for Petroleum, Natural Gas and Biofuels (ANP), the fuel regulatory agency in Brazil. It is worth mentioning that, so far, ANP has not yet regulated butanol/diesel blends. These specification limits are related to pure and commercial diesel and were adopted in this work just for comparison reasons. The limits for $\mathrm{S} 10$ diesel comprise the range from 2.0 to $4.5 \mathrm{cSt}$ and for the S500 diesel, from 2.0 to 5.0 cSt.

As observed in Tables 1 and 2, both the initial value and the percent variation of the kinematic viscosity were higher along the S500 blends series compared to that observed for the S10 series, demonstrating a greater impact of the butanol addition on the more viscous S500 diesel matrix.

Such differences in viscosities are mainly attributed to the natural hydrocarbon chain variation between both diesel matrices. Some minor contributions can be specifically related to the effects of sulfur compounds like mercaptans (R-S-H radical), disulfides (R-S-R radicals) or heterocyclics, which tend to be larger and heavier than the corresponding hydrocarbons or butanol molecules, increasing their resistance to flow, relative to each other.

Figure 1 shows the kinematic viscosity curve behavior of the blends produced with S10 and S500 diesel as a function of the butanol content. It can be noted that the viscosity reduction in blends was not 
Table 1. Kinematic viscosity of butanol/S10 diesel blends.

\begin{tabular}{cccc}
\hline \multirow{2}{*}{$\begin{array}{c}\text { Butan-1-ol } \\
(\mathbf{m a s s} \%)\end{array}$} & $\begin{array}{c}\text { Kinematic } \\
\text { Viscosity (cSt) }\end{array}$ & $\begin{array}{c}\text { 2-methylpropan-1-ol } \\
\text { (mass\%) }\end{array}$ & $\begin{array}{c}\text { Kinematic } \\
\text { Viscosity (cSt) }\end{array}$ \\
\cline { 5 - 5 } $\mathbf{X} \pm \mathbf{s d}^{*}$ & & 2.29 & $\mathbf{X} \pm \mathbf{s d}^{*}$ \\
\hline 2.38 & $2.500 \pm 0.004$ & 4.75 & $2.519 \pm 0.005$ \\
4.77 & $2.438 \pm 0.005$ & 7.10 & $2.465 \pm 0.003$ \\
7.23 & $2.389 \pm 0.003$ & 9.52 & $2.423 \pm 0.005$ \\
9.63 & $2.351 \pm 0.002$ & 11.94 & $2.393 \pm 0.001$ \\
12.07 & $2.328 \pm 0.009$ & 14.42 & $2.367 \pm 0.004$ \\
14.51 & $2.292 \pm 0.004$ & 16.84 & $2.347 \pm 0.003$ \\
16.98 & $2.269 \pm 0.006$ & 19.27 & $2.319 \pm 0.009$ \\
19.41 & $2.243 \pm 0.006$ & 21.74 & $2.310 \pm 0.006$ \\
21.89 & $2.231 \pm 0.005$ & 24.26 & $2.305 \pm 0.006$ \\
24.38 & $2.211 \pm 0.001$ & 26.58 & $2.307 \pm 0.004$ \\
26.72 & $2.201 \pm 0.005$ & 29.05 & $2.302 \pm 0.005$ \\
29.30 & $2.192 \pm 0.003$ & &
\end{tabular}

*Standard deviation

Table 2. Kinematic viscosity of butanol/S500 diesel blends.

\begin{tabular}{|c|c|c|c|}
\hline \multirow{2}{*}{$\begin{array}{c}\text { Butan-1-ol } \\
\text { (mass\%) }\end{array}$} & $\begin{array}{c}\text { Kinematic } \\
\text { Viscosity (cSt) } \\
\end{array}$ & \multirow{2}{*}{$\begin{array}{l}\text { 2-methylpropan-1-ol } \\
\text { (mass\%) }\end{array}$} & $\begin{array}{c}\text { Kinematic } \\
\text { Viscosity (cSt) } \\
\end{array}$ \\
\hline & $\mathbf{X} \pm \mathbf{s d}^{*}$ & & $\mathbf{X} \pm \mathbf{s d}^{*}$ \\
\hline 2.27 & $2.856 \pm 0.006$ & 2.25 & $2.882 \pm 0.011$ \\
\hline 4.53 & $2.776 \pm 0.006$ & 4.44 & $2.797 \pm 0.005$ \\
\hline 6.87 & $2.702 \pm 0.004$ & 6.80 & $2.742 \pm 0.007$ \\
\hline 9.26 & $2.645 \pm 0.005$ & 9.19 & $2.695 \pm 0.003$ \\
\hline 11.62 & $2.598 \pm 0.005$ & 11.58 & $2.658 \pm 0.004$ \\
\hline 14.06 & $2.550 \pm 0.002$ & 13.93 & $2.636 \pm 0.013$ \\
\hline 16.58 & $2.509 \pm 0.004$ & 16.54 & $2.595 \pm 0.004$ \\
\hline 19.04 & $2.479 \pm 0.002$ & 18.81 & $2.571 \pm 0.003$ \\
\hline 21.41 & $2.450 \pm 0.002$ & 21.22 & $2.553 \pm 0.002$ \\
\hline 23.79 & $2.421 \pm 0.003$ & 23.67 & $2.540 \pm 0.005$ \\
\hline 26.27 & $2.400 \pm 0.004$ & 26.07 & $2.525 \pm 0.002$ \\
\hline 28.73 & $2.378 \pm 0.002$ & 28.48 & $2.520 \pm 0.005$ \\
\hline
\end{tabular}

*Standard deviation

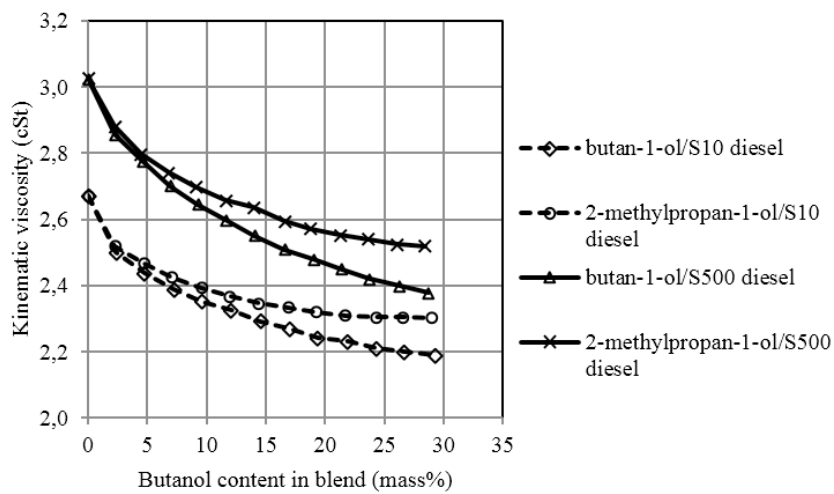

Figure 1. Kinematic viscosity curves of butanol/diesel blends in function of the butanol content in blend (mass\%).

linear, so that the data adjustment to a logarithmic function provided better determination coefficients $\left(\mathrm{R}^{2}\right)$, greater than 0.997 and 0.980 for S10 blends prepared with butan-1-ol and the 2-methylpropan-1ol, respectively. For all S500 blends, the logarithmic $\mathrm{R}^{2}$ coefficients were greater than 0.998 .

All the S10 and S500 blends prepared with butan1 -ol resulted in lower viscosity than those with 2-methylpropan-1-ol. This effect is consistent with
D' Aprano et al. (1981) and can be attributed to the 2-methylpropan-1-ol branched chain, which tends to form bulky oligomers between the alcohol molecules with lower flow capacity. The separation between each pair of curves of same diesel matrix exposes the different contribution of each butanol isomer structure on the kinematic viscosity, an effect intensified by the increase of the alcohol content.

Two important factors should be considered for understanding the kinematic viscosity behavior observed for butanol/diesel blends in Figure 1: the compound structures constituting the fuel and the resultant interaction forces present among the molecules. The hydrocarbon long chains of diesel (typically 12 to 20 carbon atoms) favor a lower flow between its molecular layers, whereas in the case of butanol, the shorter molecular structure has less resistance to flow. The hydrogen bonds formed between butanol $\mathrm{OH}$ groups compete in an opposite effect, making the molecular flow more difficult, keeping them strongly united.

In blends with diesel, butanol molecules undergo a sort of "solvation" by the larger diesel hydrocarbons, making them more spaced and weakening the interactions between hydroxyl groups. So, in an overall view of Figure 1, it is possible to assume that even hydrogen bond forces were not strong enough to avoid the kinematic viscosity reduction caused by its short molecules. On the other hand, it is also observed that, as the butanol content in the blends increases, the interactions between the $\mathrm{OH}$ groups become more prominent and the kinematic viscosity reduction rate becomes smaller, which confers the logarithmic pattern of the curve.

In terms of the automotive compression ignition engine operation, lower blend viscosities may result in the formation of more sprayed droplets in the injection system than pure diesel, consequently providing higher fuel blend dispersion and penetration capacities inside the chamber. However, in view of the presented viscosities results and considering the diesel specification limits of ANP, no significant impact on the injector atomization, line leakage or power loss would be expected for tested blends.

Some loss of the capacity of the tested blends to lubricate some engine parts, such as rotary pumps and injectors may also be observed, in consequence of the kinematic viscosity reduction. For the S500 diesel blends, this loss should be less critical than those produced with S10 diesel, since the sulfur-containing polar compounds contribute to the formation of bulkier and heavier oligomers.

\section{Volatility}

Distillation showed a strong inflection along the initial curve region (Figures 2 and 3). After the 


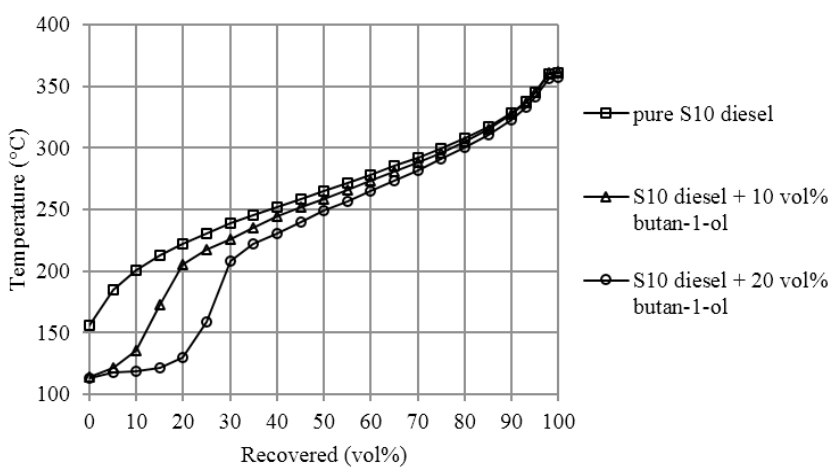

(a)

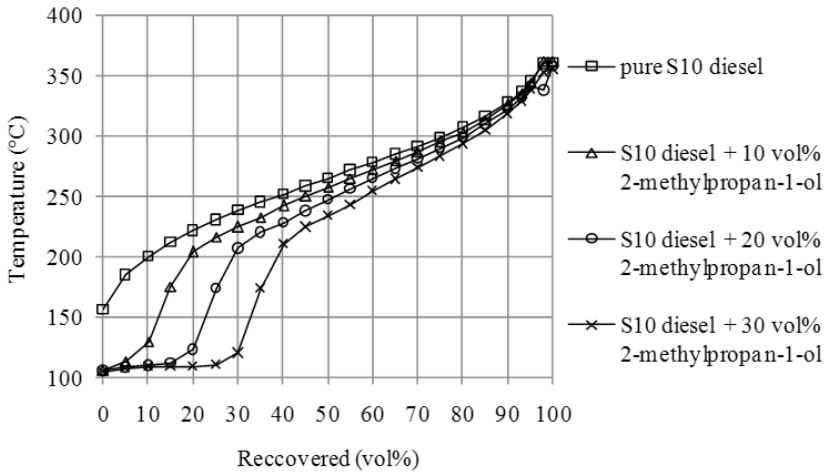

(b)

Figure 2. Comparison of distillation curves for (a) pure S10 diesel versus S10 blends containing 10 and 20 mass \% of butan-1-ol and (b) pure S10 diesel versus S10 blends containing 10, 20 and 30 mass\% of 2-methylpropan-1-ol.

total butanol evaporation, first to be distilled out, a subsequent return to the normal diesel curve was observed, at higher distillation temperatures. Indeed, the presence of butanol, a lighter and volatile compound, increased the rate of recovered volume, resulting in a lower temperature to reach each distillation point, when compared to diesel hydrocarbons (boiling points varying between 150 and $470{ }^{\circ} \mathrm{C}$ ). The shape of the butanol/diesel distillation curves obtained here are similar to each other, but less pronounced than that observed by Matuszewska et al. (2013) for ethanoldiesel blends.

Also in Figures 2 and 3 it is possible to observe a formation of a plateau, caused by the interaction between the butanol and diesel hydrocarbons, which contributes to the appearance of an azeotrope-like compound. It is noted that the portion of the curve between $0 \%$ and $25 \%$ recovered volume is practically a straight line, typical behavior of a pure substance. Butanol is distilled over a narrow temperature range and the extension of the plateau responds proportionally to the butanol content in blends, prolonging the curve inflection.

In Brazil, the ANP establishes T10, T50, T85 and T95 limits for diesel. For all blends, T10 was the most critical parameter, extrapolating ANP limits (min.

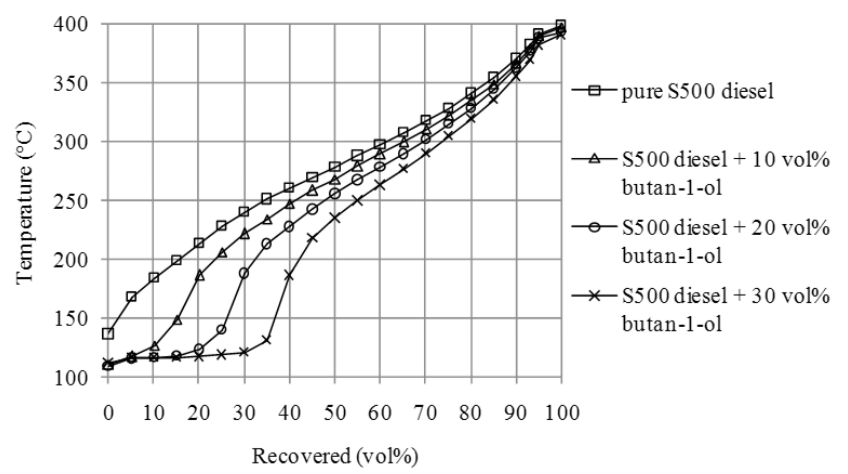

(a)

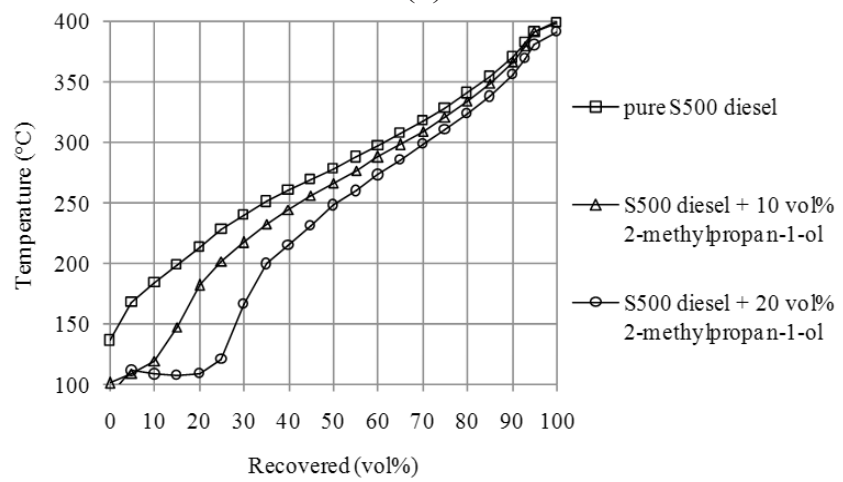

(b)

Figure 3. Distillation curves comparison of (a) pure S500 diesel versus S500 blends containing 10, 20 and 30 mass \% of butan-1-ol and (b) pure S500 diesel versus S500 blends containing 10 and 20 mass $\%$ of 2-methylpropan-1-ol.

$180.0^{\circ} \mathrm{C}$ ) taken as reference. Temperatures up to 118.7 ${ }^{\circ} \mathrm{C}$ and $116.9^{\circ} \mathrm{C}$ were registered for blends with butan1-ol and up to $109.1^{\circ} \mathrm{C}$ and $107.7{ }^{\circ} \mathrm{C}$ for blends with 2-methylpropan-1-ol, respectively. T50 temperature was less affected, although some blends with higher butanol content (from 22.5 mass \%) extrapolated ANP limits for pure $\mathrm{S} 10\left(245-295^{\circ} \mathrm{C}\right)$ and S500 diesel (245$310{ }^{\circ} \mathrm{C}$ ). No major deviations were observed for T85 and $\mathrm{T} 90$.

It is worth mentioning that the heating rate maintenance required by ASTM D86 for the distillation course (between 4 and $5 \mathrm{~mL} \mathrm{~min}^{-1}$ ) became more difficult with the increase of the butanol content in blends, hampering or even not allowing the completion of analysis, since in some cases the heating rate reached values even higher than that allowed by the test, mainly during the abrupt evaporation of butanol from the distillation flask, about $108^{\circ} \mathrm{C}$ for 2-methylpropan-1-ol and 118 ${ }^{\circ} \mathrm{C}$ for butan-1-ol.

For this reason, some distillation analyses were not concluded for S10 diesel blends containing more than 25.0 mass \% of butan-1-ol and also for S500 diesel blends containing more than 22.5 mass $\%$ of 2-methylpropan-1-ol, which explain the missing curves in Figures 2 (a) and 3 (b). 


\section{Ignition Quality}

The cetane number values and corresponding ignition delay results obtained for each tested blend are shown in Tables 3 and 4. The blends had the cetane number progressively reduced by the increase of the butanol content and, more intensively, for blends prepared with the branched isomer, 2-methylpropan1-ol. The loss in ignition quality in relation to the pure diesel was approximately $31 \%$ and $33 \%$ for the S10 blends and 25\% and 29\% for S500 diesel blends, respectively.

A comparison of Tables 3 and 4 shows that pure S500 diesel has a lower cetane number than that of pure S10 diesel, a difference that extends over the whole blends series. In this context, the relationship between the kinematic viscosity and the cetane number should be mentioned, so that an increase in ignition delay is also related to the worst spray atomization due to a higher viscosity of S500 blends. Thus, larger fuel droplet size resulted in a higher ignition delay.

The higher content of sulfur compounds in the S500 diesel entails the intensification of dipoledipole interactions, stronger than the dipole-induced dipole hydrocarbon types. Thus, an additional amount of energy (heat) had to be extracted from the IQT combustion chamber for the S500 blends vaporization, delaying the time to achieve the temperature and pressure equilibrium propitious for combustion.

Figure 4 shows the linear behavior observed for the IQT cetane number as a function of the increasing butanol content in blends, providing a satisfactory correlation $\left(\mathrm{R}^{2}\right)$ higher than 0.99 for all the curves.

The Brazilian legislation for diesel establishes cetane number minimum limits of 48.0 and 42.0 for the commercial S10 and S500, respectively. Once again, it

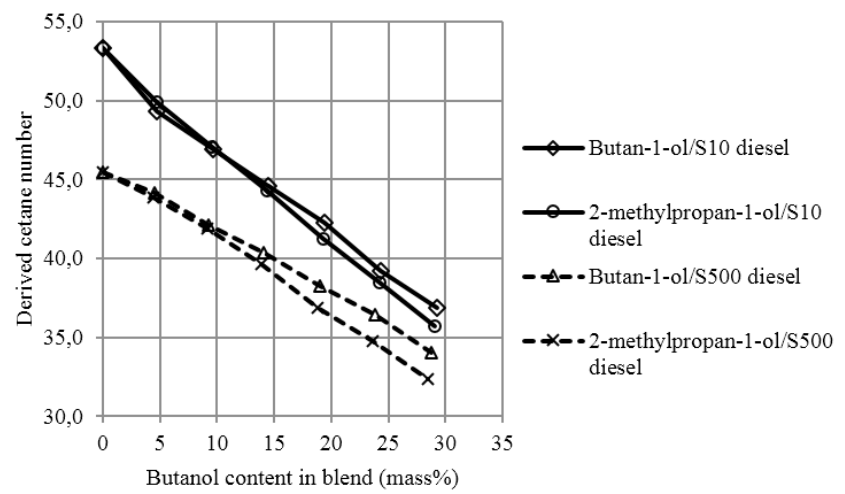

Figure 4. Cetane number curves for S10 and S500 butanol/diesel blends as a function of the butanol content (mass \%).

must be highlighted that these values are given in the legislation for diesel and not for butanol/diesel blends, which are not yet specified by ANP.

For a same diesel matrix, the different behavior of the cetane number curves between the normal and branched butanol isomers is related to the degree of interaction of its molecules with the oxygen of air and radical stabilization during the combustion. Branched 2-methylpropan-1-ol structure provides greater steric resistance for oxygen interaction and, at the same time, greater radical stabilization on tertiary carbon, making the molecule less reactive and, consequently, resulting in a slower combustion reaction.

Due to the formation of hydrogen bonds between the butanol molecules, the enthalpy of vaporization, that is, the energy required for its molecules to be completely vaporized, is known to be higher than that of the diesel hydrocarbons, in which dipole-induced dipole interactions predominate. In kinetic terms, as far as the combustion occurs only in vapor state, this

Table 3. Cetane number of butanol/S10 diesel blends.

\begin{tabular}{cccccc}
\hline $\begin{array}{c}\text { Butan-1-ol } \\
\text { (mass\%) }\end{array}$ & $\begin{array}{c}\text { Cetane } \\
\text { number }\end{array}$ & $\begin{array}{c}\text { Ignition } \\
\text { delay (ms) }\end{array}$ & $\begin{array}{c}\text { 2-methyl-propan-1-ol } \\
\text { (mass\%) }\end{array}$ & Cetane number & $\begin{array}{c}\text { Ignition } \\
\text { delay (ms) }\end{array}$ \\
\hline Pure diesel & $53.35 \pm 1.07$ & $3.817 \pm 0.084$ & Pure diesel & $53.35 \pm 1.07$ & $3.817 \pm 0.084$ \\
4.77 & $49.31 \pm 0.94$ & $4.161 \pm 0.087$ & 4.75 & $49.88 \pm 1.35$ & $4.108 \pm 0.119$ \\
9.63 & $46.95 \pm 1.30$ & $4.391 \pm 0.135$ & 9.52 & $47.04 \pm 0.83$ & $4.382 \pm 0.086$ \\
14.51 & $44.57 \pm 1.06$ & $4.652 \pm 0.118$ & 14.42 & $44.31 \pm 1.22$ & $4.682 \pm 0.137$ \\
19.41 & $42.29 \pm 0.98$ & $4.932 \pm 0.126$ & 19.27 & $41.27 \pm 0.87$ & $5.070 \pm 0.119$ \\
24.38 & $39.21 \pm 0.70$ & $5.370 \pm 0.105$ & 24.26 & $38.45 \pm 0.57$ & $5.490 \pm 0.090$ \\
29.30 & $36.85 \pm 0.51$ & $5.761 \pm 0.090$ & 29.05 & $35.71 \pm 0.51$ & $5.971 \pm 0.098$ \\
\hline
\end{tabular}

Table 4. Cetane number of butanol/S500 diesel blends.

\begin{tabular}{ccccc}
\hline $\begin{array}{c}\text { Butan-1-ol } \\
(\mathbf{m a s s} \%)\end{array}$ & $\begin{array}{c}\text { Cetane } \\
\text { number }\end{array}$ & $\begin{array}{c}\text { Ignition } \\
\text { delay }(\mathbf{m s})\end{array}$ & $\begin{array}{c}\text { 2-methyl-propan-1-ol } \\
(\mathbf{m a s s} \%)\end{array}$ & $\begin{array}{c}\text { Ignition } \\
\text { delay }(\mathbf{m s})\end{array}$ \\
\hline Pure diesel & $45.50 \pm 0.87$ & $4.547 \pm 0.097$ & Pure diesel & $4.547 \pm 0.097$ \\
4.53 & $44.12 \pm 0.64$ & $4.705 \pm 0.076$ & 4.44 & $45.50 \pm 0.87$ \\
9.26 & $42.10 \pm 0.50$ & $4.958 \pm 0.066$ & 9.19 & $43.84 \pm 0.45$ \\
14.06 & $40.36 \pm 0.43$ & $5.198 \pm 0.062$ & 13.93 & $41.89 \pm 0.49$ \\
19.04 & $38.28 \pm 0.69$ & $5.517 \pm 0.108$ & 18.81 & $39.62 \pm 1.13$ \\
23.79 & $36.41 \pm 0.94$ & $5.840 \pm 0.160$ & 23.67 & $36.90 \pm 0.58$ \\
28.73 & $34.02 \pm 0.44$ & $6.312 \pm 0.093$ & 28.48 & $34.79 \pm 0.66$ \\
\hline
\end{tabular}


represents a higher activation energy to be overcome for burning the alcohol.

Thus, because of the higher butanol enthalpy of vaporization, a greater amount of heat had to be captured from the system to allow the blend vaporization compared to pure S10 and S500 diesel, resulting in a greater energy deficit (reduction of temperature) inside the IQT-LM combustion chamber. Therefore, a longer time was necessary to reach the ideal temperature and pressure conditions for auto-ignition.

Figure 5 shows the experimental IQT stack time plot obtained for pure $\mathrm{S} 10$ diesel and its respective blends with 10 mass $\%, 20$ mass $\%, 30$ mass $\%$ of butan1-ol content, where it is possible to observe the exact
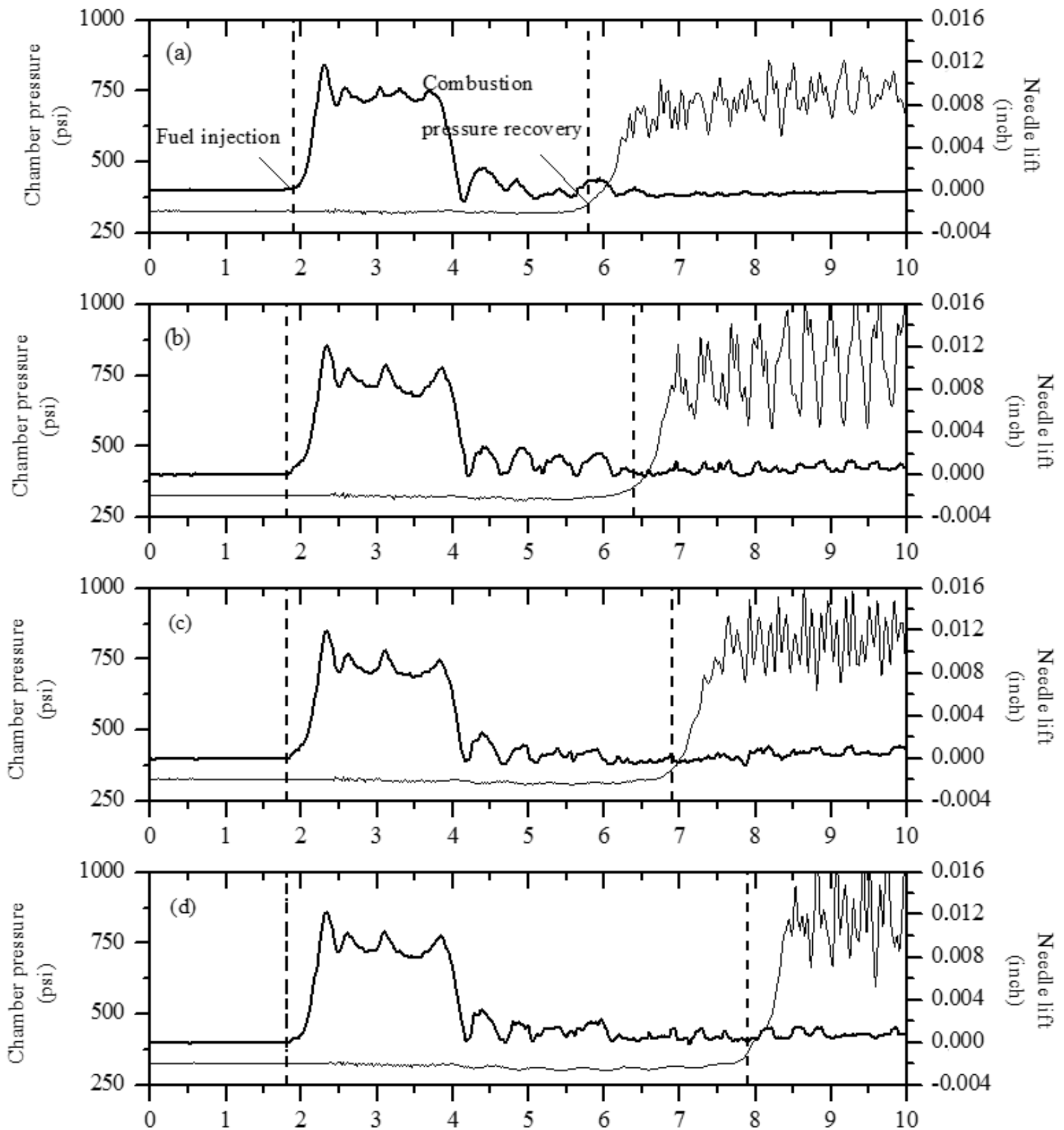

Time (ms)

Figure 5. IQT stack time plot for (a) pure S10 diesel and (b, c, d) S10 blends with 10, 20 and 30 mass \% of butan-1-ol content, respectively. Distance between vertical dashed lines in each plot indicates the delay time (in milliseconds) from fuel injection to its combustion. 
fuel sample injection time and the pressure chamber increase after combustion. It also becomes clear in Figure 5 that the ignition delay is proportional to the increasing butanol content in blends.

\section{CONCLUSIONS}

In this work important investigations concerning the viscosity, volatility and ignition quality of butanol/diesel blends were reported, considering the specificities of both linear or branched butanol isomers and two different types of diesel matrices, varying in hydrocarbon composition and sulfur content (10 ppm and $500 \mathrm{ppm}$ ).

Results showed that the linear or branched structure of butanol played a key role on the final blend characteristics evaluated, affecting the intensity of the hydrogen bonds, van der Waals forces and intermolecular interactions (packaging/solvation) between butanol molecules and diesel hydrocarbons. Interesting behavior differences were observed, especially for viscosity and ignition quality, depending on the carbon structure of butanol and the diesel matrix composition. The higher sulfur content and the branched structure of butanol contributes, together, to a higher viscosity and lower cetane number of blends, so that the reduction of these properties was more intense when using S500 matrix.

An overall reduction of the blend kinematic viscosity was observed following a logarithmic trend, but that did not extrapolate the limits accepted by Brazilian legislation. Volatility showed an intense reduction of all boiling temperatures along the distillation curve, especially in the initial region, reestablishing itself at higher temperatures. Two important points of the distillation curve (T10 and T50) resulted in very high values in blends with diesel. The points from T85 onwards were less affected since they are in a region of temperature far from the butanol boiling point. Loss in ignition quality was observed for all tested blends, reducing linearly with increasing butanol content and being more pronounced for blends produced with 2-methylpropan-1-ol, whose branched structure does not favor combustion due to the steric resistance and radical stabilization factors.

The results presented here open new opportunities for studies aimed at improving the volatility and quality of ignition characteristics, minimizing the experimental deviations observed in this work. Other possibilities include tests with new additives or multi-component blends (ex: ternary blends butanol/biodiesel/diesel) to meet desired quality criteria, especially for blends with high butanol contents.

\section{ACKNOWLEDGEMENTS}

The authors thank ANP, CAPES, CNPq and FAPDF for partial financial support. The authors are in debt with Distribuidora Total S.A. for gently providing pure S10 and S500 diesel. PAZS thanks CNPq for his research fellowship.

\section{REFERENCES}

Atmanl1, A.; Ileri, E.; Yuksel, B.; Experimental investigation of engine performance and exhaust emissions of a diesel engine fueled with diesel-nbutanol-vegetable oil blends. Energy Convers. Manage., 81, 312-321 (2014).

Altun, S.; Oner, C.; Yas, F.; Adin, H.; Effect of n-butanol blending with a blend of diesel and biodiesel on performance and exhaust emissions of a diesel engine. Ind. Eng. Chem. Res., 50, 94259430 (2011).

Barrios, C. C.; Martín, C.; Domínguez-Sáez, A.; Álvarez, P.; Pujadas, M.; Casanova, J.; Effects of the addition of oxygenated fuels as additives on combustion characteristics and particle number and size distribution emissions of a TDI diesel engine. Fuel, 132, 93-100 (2014).

Belincanta J.; Alchorne A.; Teixeira da Silva, M.; The brazilian experience with ethanol fuel: aspects of production, use, quality and distribution logistics. Braz. J. Chem. Eng., 33(4), 1091-1102 (2016).

Boretti, A.; Advantages of converting Diesel engines to run as dual fuel ethanol-Diesel. Appl. Therm. Eng., 47, 1-9 (2012).

Chen, B.; Liu, X.; Liu, H.; Wang, H.; Kyritsis, D. C.; Yao, M.; Soot reduction effects of the addition of four butanol isomers on partially premixed flames of diesel surrogates. Combust. Flame, 177, 123136 (2017).

Chen, G.; Shen, Y.; Zhang, Q.; Yao, M.; Zheng, Z.; Liu, H.; Experimental study on combustion and emission characteristics of a diesel engine fueled with 2,5-dimethylfuran-diesel, n-butanol-diesel and gasoline-diesel blends. Energy, 54, 333-342 (2013).

Chen, Z.; Liu, J.; Han, Z.; Du, B.; Liu, Y.; Lee, C.; Study on performance and emissions of a passenger-car diesel engine fueled with butanol-diesel blends. Energy, 55, 638-646 (2013).

Cheng, X.; Li, S.; Yang, J.; Liu B.; Investigation into partially premixed combustion fueled with N-butanol-diesel blends. Renew. Energ., 86, 723732 (2016).

D'Aprano, A.; Donato, D. I.; Agrigento, V.; Static dielectric constant, viscosity and structure of pure isomeric pentanols. J. Solution Chem., 10, 9, 673680 (1981). 
Dogan, O.; The influence of n-butanol-diesel fuel blends utilization on a small diesel engine performance and emissions. Fuel, 90, 2467-2472 (2011).

Garcia, V.; Päkkillä, J.; Ojamo, H.; Muurinen, E.; Keiski, R.; Challenges in biobutanol production How to improve the efficiency?. Renew. Sust. Energ. Rev., 15, 964-980 (2011).

Giakoumis, E. G.; Rakopoulos, C. D.; Dimaratos, A. M.; Rakopoulos, D. C.; Exhaust emissions with ethanol or n-butanol diesel fuel blends during transient operation. A review. Renew. Sust. Energ. Rev., 17, 170-190 (2013).

He, B.; Yuan, J.; Liu, M.; Zhao, H.; Combustion and emission characteristics of a n-butanol HCCI engine. Fuel. 115, 758-764 (2015).

Hönig, V.; Smrčka, L.; Ilves, R.; Küüt, A.; Adding biobutanol to diesel fuel and impact on fuel blend parametres. Agron. Res., 13(5), 1227-1233 (2015).

Imtenan, S.; Masjuki, H. H.; Varman, M.; Fattah, I. M. R.; Evaluation of n-butanol as an oxygenated additive to improve combustion-emissionperformance characteristics of a diesel engine fuelled with a diesel-calophylluminophyllum biodiesel blend. RSC Adv., 5, 17160-17170 (2015).

Kim, D. H.; Lee, J. M.; Park, E. H.; Song, J. H.; Park, S. I.; Engine performance and toxic gas analysis of biobutanol - blended gasoline as vehicle fuel. Int. J. Automot. Techn., 12(3), 409-416 (2011).

Kozak, M.; An application of butanol as a diesel fuel component and its influence on exhaust emissions. TEKA Kom.Mot.i Energ. Roln., 11c, 126-133 (2011).

Kumar, S.; Cho, J. H.; Park, J.; Moon, I.; Advances in diesel-alcohol blends and their effects on the performance and emissions of diesel engines. Renew. Sust. Energ. Rev., 22, 46-72 (2013).

Lapuerta, M.; García-Contreras, R.; CamposFernández, J.; Dorado, M. P.; Stability, lubricity, viscosity and cold-flow properties of alcohol-diesel blends. Energy Fuels, 24, 4497-4502 (2010).

Liu, H.; Li, S.; Zheng, Z.; Xu, J.; Yao, M.; Effects of n-butanol, 2-butanol, and methyl octynoate addition to diesel fuel on combustion and emissions over a wide range of exhaust gas recirculation (EGR) rates. Appl. Energ., 112, 246-256 (2013).

Liu, H.; Ma, S.; Zhang, Z.; Zheng, Z.; Yao, M.; Study of the control strategies on soot reduction under early-injection conditions on a diesel engine. Fuel, 139, 472-481 (2015).

Lujaji, F.; Bereczky, A.; Janosi, L.; Novak, C.; Mbarawa, M.; Cetane number and thermal properties of vegetable oil, biodiesel, 1-butanol and diesel blends. J. Therm. Anal. Calorim., 102,11751181 (2010).

Matuszewska, A.; Odziemkowska, M.; Czarnocka, J.; Properties of bioethanol-diesel oil mixtures. Materials and Process for Energy, 1, 352-359 (2013).
Mehta, R. N.; Chakraborty, M.; Mahanta, P.; Parikh, P. A.; Evaluation of fuel properties of butanolbiodiesel-diesel blends and their impact on engine performance and emissions. Ind. Eng. Chem. Res., 49, 7660-7665 (2010).

Mehta, R. N.; Chakraborty, M.; Parikh, P. A.; Comparative study of stability and properties of alcohol-diesel blends. Indian J. Chem. Technol., 19, 134-139 (2012).

Nayyar, A.; Sharma, D.; Soni, S. L.; Mathur, A.; Characterization of $\mathrm{n}$-butanol diesel blends on a small size variable compression ratio diesel engine: Modeling and experimental investigation. Energ. Convers. Manage., 150, 242-258 (2017).

Norhidayah, M. T.; Mohd, R. A. M.; Wan, M. F. W. M.; Fais, A. S.; Nik, R. N. A.; Investigation of dieselethanol blended fuel properties with palm methyl ester as a co-solvent and blends enhancer. MATEC Web of Conferences, 90, 1-11 (2017).

Rakopoulos, D. C.; Rakopoulos, C. D.; Hountalas, D. T.; Kakaras, E. C.; Giakoumis, E. G.; Papagiannakis, R. G.; Investigation of the Performance and Emissions of Bus Engine Operating on Butanol/ Diesel Fuel Blends. Fuel, 89, 2781-2790 (2010).

Ramírez, A. I.; Aggarwal, S. K.; Som, S.; Rutter, T. P.; Longman, D. E.; Effects of blending a heavy alcohol $\left(\mathrm{C}_{20} \mathrm{H}_{40} \mathrm{O}\right)$ with diesel in a heavy-duty compression-ignition engine. Fuel, 136, 89-102 (2014)

Sukjit, E.; Herreros, J. M.; Dearn, K. D.; GarcíaContreras, R.; Tsolakis, A.; The effect of the addition of individual methyl esters on the combustion and emissions of ethanol and butanol-diesel blends. Energy, 42, 364-374 (2012).

Valentino, G.; Corcione, F. E.; Iannuzzi, S. E.; Serra, S.; Experimental Study on Performance and Emissions of a High Speed Diesel Engine Fuelled With n-Butanol Diesel Blends Under Premixed Low Temperature Combustion. Fuel, 92, 295-307 (2012).

Zheng, M.; Han, X.; Asad, U.; Wang, J.; Investigation of butanol-fuelled HCCI combustion on a high efficiency diesel engine. Energ. Convers. Manage., 98, 215-224 (2015).

Zheng, Z.; Li, C.; Liu, H.; Zhang, Y.; Zhong, X.; Yao, M.; Experimental study on diesel conventional and low temperature combustion by fueling four isomers of butanol. Fuel, 141, 109-119 (2015).

Zheng, Z.; Yue, L.; Liu, H.; Zhu, Y.; Zhong, X.; Yao, M.; Effect of two-stage injection on combustion and emissions under high EGR rate on a diesel engine by fueling blends of diesel/gasoline, diesel/ n-butanol, diesel/gasoline/n-butanol and pure diesel. Energy Conversion and Management., 90, 1-11 (2015). 